by following the method adopted in preparing the following types :-

1. One teaspoonful of bread jelly or frame food, well rubbed up with 10 drops of cream (dripping, Lahmann's vegetable milk or emulsion of almond oil), two teaspoonfuls of raw meat juice, and water to make $1 \frac{1}{2}$ ounces.

2. One teaspoonful of bread jelly or frame food, one half teaspoonful of virol, one half ounce of strong beef tea, or 15 drops of invalid bovril, and water make $1 \frac{1}{2}$ ounces.

3. Prideaux's casumen half teaspoonful, Mellin's food half teaspoonful, virol half teaspoonful, and water to $1 \frac{1}{2}$ ounces.

4. Frame food one teaspoonful, cream 10 drops, or virol 15 drops, Benger's pepton jelly one teaspoonful, water to $1 \frac{1}{2}$ ounces.

If necessary a few drops of brandy may be added to all of these mixtures. For an infant of four months $1 \frac{1}{2}$ ounce of any of the above mixtures, every two and a-half or three hours, is at first amply sufficient. Sterilised water flavoured with a little Bovril or other stimulating preparation should be given freely between the regular times of feeding.

In conclusion, I would strongly advise any practitioner who has the management of one of these cases to secure the services of a trained nurse, to follow the effect of his treatment by weighing the infant carefully at least twice a week, and to keep a systematic record of the progress; to exercise the greatest patience, and to be content at first with any improvement however slow.

\section{HAY FEVER.}

SUFFERERS from hay fever will now be rejoicing, no doubt, that their special malady, which has hitherto made them look forward with something like dread to the approach of early summer, is at this moment the subject of extensive experimental research at the hands of Professor Dunbar, of Hamburg, and that so far as his investigations go, judging from Sir Felix Semon's report in the British Medical Journal of March 28th and April 18th, there seems to be a reasonable likelihood that in the near future medical men will be in a position to treat the complaint on a basis of rational pathology and therapeutics. Up to the present time, the only sure way of obtaining relief from the affection has been to run away from it, and to abide the summer in some place where the baleful pollen is not, a course obviously impossible for the many. Now, however, according to Professor Dunbar, the toxin has been discovered. He has isolated from the pollen of certain grasses a toxic substance which, when applied in very dilute solution to the eyes or nostrils of individuals who are subject to hay fever, produces within a few minutes the characteristic local symptoms of the complaint. The toxin solution has no effect upon one who is not a sufferer from hay fever. By injecting the pollen of various grasses into the circulation of certain animalsrabbits, goats and horses-Professor Dunbar has succeeded, he believes, in producing an active antitoxin, which, when applied to the eyes and nostrils of hay-fever patients in whom the local symptoms have been produced artificially by the previous employment of the toxin, immediately quells the subjective symptoms, and in a few minutes causes the objective signs to subside. Grasses appear to be the chief offenders in causing the affection, for Professor Dunbar has failed to discover the toxin in the pollen of roses and many other flowers. The toxin was obtained in sufficient quantity for experimental purposes by extracting the crushed pollen of maize with saline solutions at the body temperature for about six hours, and by precipitating the toxin from the solution with alcohol. The antitoxin was obtained by injecting the toxin into horses. A full report of Professor Dunbar's investigations will be welcomed with a considerable amount of interest by the medical profession at large.

\section{RETINAL HAMORRHAGES IN FRACTURE OF THE SKULL.}

As the result of some interesting observations on the eyes of persons who had died from fracture of the base of the skull or from intracranial hæmorrhage involving the subarachnoid space without fracture, Dr. Fleming ${ }^{1}$ draws some- conclusions which, if established as correct in the light of further inquiry, should make an important addition to our knowledge of these conditions. He found that, on examining the eyes of persons who had died from fracture of the base of the skull in which there had been considerable effusion of blood into the subarachnoid space, retinal hæmorrhages were usually present, and that where the subarachnoid effusion was unilateral the retinal hæmorrhages were as a rule limited to the same side. The hæmorrhages in the retina were usually massive, or of irregular outline, and were situated at some distance from the optic disc. In cases where the subarachnoid effusion comes on gradually no hæmorrhages occur in the retina. Dr. Fleming mentions twelve cases of fractured skull on which he bases his conclusions. Eleven were cases of fractured base and in one there was a fracture of the squamous part of one temporal bone. He divides these cases into three groups: (1) Five cases in which the subarachnoid effusion was mostly unilateral and retinal hæmorrhages were present but confined to the eye on the same side ; (2) two cases in which the effusion was almost equally marked on the two sides, and in which there were retinal hæmorrhages in both eyes; (3) five cases in which no retinal hæmorrhages were found. In all these, with two exceptions, there was but little subarachnoid hæmorrhage, or an effusion of apparently slow onset, and in one of these pressure seems to have interfered with the passage of blood into the intersheath spaces of the optic nerve. In order to exclude the fallacy as to the retinal hæmorrhages being due to the concussion or other conditions associated with fracture of the skull, four cases of subarachnoid effusion not due to fracture were examined. In three of these retinal hæmorrhages were found. In one they were present in both eyes, in the other two they were confined to the side of the chief subarachnoid effusion alone. Dr. Fleming thinks that it is reasonable to conclude that a subarachnoid hæmorrhage, if sufficiently rapid in its development, will cause retinal hæmorrhages, and that if the effusion is unilateral the hæmorrhages will be confined mostly to the affected side.

1 Edinburgh Medical Journal, April. 